\title{
2008/8
}

An integrated model for warehouse and inventory planning

Géraldine Strack and Yves Pochet 
CORE

Voie du Roman Pays 34

B-1348 Louvain-la-Neuve, Belgium.

Tel (32 10) 474304

Fax (32 10) 474301

E-mail: corestat-library@uclouvain.be http://www.uclouvain.be/en-44508.html 


\title{
CORE DISCUSSION PAPER
}

$2008 / 8$

\section{An integrated model for warehouse and inventory planning}

\author{
Géraldine STRACK ${ }^{1}$ and Yves POCHET ${ }^{2}$
}

February 2008

\begin{abstract}
We propose a tactical model which integrates the replenishment decision in inventory management, the allocation of products to warehousing systems and the assignment of products to storage locations in warehousing management. The purpose of this article is to analyse the value of integrating warehouse and inventory decisions. This is achieved by proposing two methods for solving this tactical integrated model which differ in the level of integration of the inventory and warehousing decisions. A computational analysis is performed on a real world database and using multiple scenarios differing by the warehouse capacity limits. Our observation is that the total cost of the inventory and warehousing systems can be reduced drastically by taking into account the warehouse capacity restrictions in the inventory planning decisions, in an aggregate way. Moreover additional inventory and warehouse savings can be achieved by using more sophisticated integration methods for inventory and warehousing decisions.
\end{abstract}

Keywords: multi-item inventory model, tactical warehouse model, integrated model, Lagrangian relaxation.

\footnotetext{
${ }^{1}$ CORE and LSM, Université catholique de Louvain, Belgium. E-mail: Geraldine.strack@uclouvain.be ${ }^{2}$ CORE, Université catholique de Louvain, Belgium.
}

This paper presents research results of the Belgian Program on Interuniversity Poles of Attraction initiated by the Belgian State, Prime Minister's Office, Science Policy Programming. The scientific responsibility is assumed by the authors. 


\section{Introduction}

Nowadays, managers are faced with the need to deliver a high level of service with minimal warehouse and inventory cost. As it has been shown in surveys (WERC 1986 and [1]), the order picking activity represents $65 \%$ of the total cost and $50 \%$ of the workforce of a warehouse. This proportion is even more important if we consider distribution warehouses where the main activity (the only added value) is to receive pallets of items from vendors, stock them and deliver customer orders containing different items. In addition, with the improvement in information technology, it becomes possible to develop tools which can help managers to handle warehouse and inventory issues more efficiently.

At all classical levels of decision (strategic, tactical and operational) [13],[14],[9], warehouse managers have to tackle problems which can be divided into two broad classes: warehouse management and inventory management problems.

Regarding warehouse management issues, managers have to decide where to assign the products inside the warehouse. Strategic decisions concern issues such as the size of the warehouse and the technical specifications of the warehouse. Tactical decisions concern issues such as the layout of the warehouse and the sizing of the various areas inside the warehouse [6],[16]. Finally, operational decisions deal with control policies and routing problems. Concerning inventory management, managers must decide which product, and how much of each product need to be stored in the warehouse. In this class, strategic decisions concern the size and the design of the warehouse (a common decision with warehouse management) and more specific decisions such as the configuration of the inventory management decision systems. The tactical decisions concern issues such as the operating hours, the replenishment policies and work force size. On the last level (operational), problems such as "what to produce or deliver", "when" and "on which machine or by whom" are considered. (see also [11] for more details)

All those decisions are interrelated but are dealt with independently [9]. Up to now, those issues (strategic, tactical and operational decisions) are handled in a pyramidal top-down approach where the flexibility of decisions decreases from top to bottom. Strategic decisions are first taken and then create limits to decisions taken at the tactical and operational levels. For example, once the size and the design of the warehouse are fixed, these decisions will have to be respected when replenishment policies have to be designed as well as when the size of the different warehousing areas has to be optimized (see [9], [5] for more examples).

On top of this, decisions taken at each level of the pyramid are also handled independently and sequentially [13]. For example, concerning warehousing decisions taken at the tactical level, Jeroem P. van den Berg [13] has introduced a classification of the different problems faced by managers. He has proposed four different classes of decisions.

The first class tackles issues related to the assignment of products across warehousing systems. Warehousing systems differ by the level of automation used. The author [13] gives three levels of automation: manual order pickers where pickers ride along the picking position (picker to product systems), AS/RS order picker 
or carousel where products are picked by machines and sorted by people (product to picker systems) and totally automated order pickers (robot technology). In addition, warehouses are often divided in areas according to the unit load retrieval. Usually, a forward area is used for order picking of units of items frequently ordered and a reserve area is used either for replenishment of the forward area or for order picking of cartons or pallets of items or for products not ordered frequently enough.

The second class of problems concern the clustering of correlated products in

such a way that products that are frequently ordered together are assigned to locations close to each other.

The third class of problems concerns the workload balancing problem across the warehouse and the last class concern the assignment of products to storage locations in order to minimize the distance traveled for order replenishment and picking.

We propose a tactical model which integrates more phases of the decision process: the replenishment decision in the inventory management, the allocation of products to warehousing systems and the assignment of products to storage locations in the warehousing management. We consider a picker to product distribution warehouse which is divided in a forward and a reserve area. Our objective is to minimize all relevant warehousing and inventory costs by optimizing the quantity of each product allocated to the forward area (by reducing the work load related to order picking), the location of the product inside the forward area and the inventory replenishment policies. Our tactical model takes the size of the warehousing systems as given (strategic decision level). Our aim is to test whether or not an integrated approach to take these inventory and warehousing decisions has some additional value, compared to the classical sequential approach.

In the second section, we will make a brief review of the literature available on the subject. The third section will introduce the model formulation and the various assumptions made. A description of the methodology used to solve the integrated model will follow in Section 4 and lastly the various computational results will be presented for an industrial test case in Section 5 .

\section{Literature review}

We give references to the different models in the field of warehouse and inventory management available in the literature. As written in Section 1, most tactical issues in warehouse and inventory management are tackled independently and sequentially. In consequence, the models developed in those two fields are presented separately.

\subsection{Forward-reserve models}

The Forward-reserve problem (FRP) is the problem of assigning products to the forward and reserve areas in order to reduce the overall work content in order picking [2]. Nowadays, most warehouses are divided in two areas: forward and reserve. The 
forward area is used for broken-case and full-case picking and the reserve area is used for pallet picking and reserve storage. Once a product is stored in the forward area (respectively the reserve area), all picks must be performed from the forward area (respectively the reserve area). When the inventory of an item stored in the forward area reaches its reorder point an internal replenishment is performed (from the reserve area to the forward area). The forward area is usually a smaller area than the reserve area where order picking takes less time and is then less costly. The critical decision concerns the choice of the products which will be stored in the forward area. Indeed, if all products are located in the forward area, the size of this area increases and the advantage of lower order picking cost vanishes. The other decision is to allocate space in the forward area for the different products.

Hackman and Rosenblatt [10] were the first to address the issues of deciding which product to store in the forward area (assignment issue) and how much to store (allocation issue). They considered a warehouse composed of a small area (forward area) where picking of products is based on an efficient (less time consuming) AS/RS automated storage and retrieval system. The reserve area is a large area (infinite capacity) handled through an inefficient manual/ semi-automated material handling system. Reception of products is made through the manual/ semi automated area and can be used to satisfy customers orders or to make internal replenishment of the AS/RS area. The question tackled in this article is to decide which and how much product must be stored in the forward area taking into account picking costs and internal replenishment costs and the capacity constraint of the forward area. They solve the problem through the greedy heuristic where the products are assigned to the forward area according to some priori ranking of the products until the space is full. This ranking is based on the comparison of the savings due to efficient picking in the AS/RS area and the cost of internal replenishment. They prove a sufficient conditions for optimality.

Frazelle et al. [3] propose a model that tackles three warehouse decisions: the size of the forward area and the allocation/ assignment of products to the forward area. They propose a model which minimizes the total warehousing costs, which depends on the size of the forward area (replenishment cost of the forward area, Reserve/forward picking cost and the cost of capital (shelvings)), under forward capacity and congestion constraints. Firstly, they show that the congestion constraint is redundant. Consequently, the optimal quantity assignment/allocation solution can be found based on Hackman and Rosenblatt (1990)[10] work. Secondly, they show that the optimal assignment for the products (forward or reserve area), considering the linear relaxation of their model, is the ranking given by Hackman and Rosenblatt 1990 [10] which is independent of the size of the forward area. They proposed an algorithm which gives a near optimal solution to their model based on the linear relaxation of their model.

J.P. van den Berg et al.[2] propose a model to solve the forward-reserve problem in the case of unit load replenishment. Those replenishments can occur during busy or idle picking periods. The objective is to minimize the number of urgent or concurrent replenishments of the forward area arriving during the busy periods. Such replenishment are needed in case of shortage during the busy period but 
should be avoid because congestion can result. Instead, replenishment activities are encouraged to take place during the previous idle period. The resulting forwardreserve model is a binary programming problem which is solved using a greedy knapsack heuristic procedure based on a linear relaxation of the initial model. In a second part of the article, they modify the model to incorporate a limit on the amount of concurrent replenishment.

\section{$2.2 \quad$ Inventory models}

The aim of inventory management is to minimize total operating costs while satisfying customer service requirements [4]. In order to accomplish this objective, an optimal ordering policy will be determined by answering to questions such as when to order and how much to order. The operating costs taken into account are the procurement costs, the holding costs and the shortage costs which are incurred when the demand of a client can not be satisfied (either lost sales costs or backorder costs)[4] [7]. There exist different inventory policies [7] : periodic review policy and the continuous review policy. The first policy implies that the stock level will be checked after a fixed period of time and an ordering decision will be made in order to complete the stock to an upper limit (order up to point), if necessary. In the second policy, the stock level will be monitored continuously. A fixed quantity will be ordered when the stock level reaches a reorder point. The order quantity will only be delivered after a fixed lead time and shortage can exist if the inventory is exhausted before the receipt of the order quantity. Those basic policies can be adapted to take into account special situation such as single or multi item models, single or multi period models, deterministic or stochastic demands, lost sales or backorder...(see [7],[11],[4] for more details and examples)

\section{Model formulation}

\subsection{Problem Description}

We consider a warehouse composed of a reserve area and a forward area. The forward area is divided into locations and each product in the forward area is allocated to a number of locations. Before the picking period, the forward area is replenished through advance replenishments from the reserve area. The level of the advance replenishment for each product corresponds to the filling of the allocated space in the forward area. Nevertheless, if the stock level in the forward area reaches some reorder point, to avoid shortages, concurrent replenishments will take place. Meanwhile, the enterprise receives external supply for all products. The issues that we address simultaneously are the decision of the routes taken by the different products in the warehouse (external supplies to the reserve area or directly to the forward area) and the quantity of the products allocated to the forward and/or the reserve area (warehouse management issues). In addition, the optimal frequency of the external supplies will be optimized as well as the safety stocks required to offer 
an adequate customer service level (inventory management issues). These issues are interrelated because the external supply cost will depend on the routes taken by the product on one hand and the location of the product in the warehouse will depend on the quantity ordered on the other hand.

\subsection{Assumptions}

First of all, we assume that the layout of the warehouse is given. By this, we mean that the size of the warehouse and of the different warehousing systems are given (forward and reserve areas). Nevertheless, we suppose that it is possible to rent external storage space if the space available in the warehouse is not sufficient to store all the products. This additional capacity is usually rented at a higher cost than the cost of the internal warehouse capacity. We suppose also that this additional capacity implies the same costs (reception cost, storage cost..) than the ones linked to the reserve area.

Different storage policies may exist: random storage policy and dedicated storage policy[4]. In a random storage policy, products are randomly assigned to a location in the warehouse. In a dedicated storage policy, each product is assigned to a specific location. In the latter case, if the product is not available in the warehouse then the location of this product will be empty and there will be unused space. The forward area, due to its purpose, will be handled through a dedicated storage policy. Concerning the reserve area, we will consider the two storage policies, the dedicated or the random.

During the picking period, different activities can occur. We have considered six main activities : concurrent and advance replenishments of the forward area from the reserve area, picking from the forward area and the reserve area, external supply of the forward area and the reserve area. We formulate some assumptions for each of those activities.

Concerning the advance replenishment of the forward area, we suppose that this activity occurs during some idle period just before the picking period and does not imply any congestion cost. Whereas, concurrent replenishments occur during the picking period when there are not enough items of a product in the forward area to satisfy the demand of that product and therefore induce congestion. Concurrent replenishment will be performed immediately when the reorder point is reached. The level of the reorder point corresponds to the average demand during the concurrent replenishment lead time, plus some safety stock. We suppose that the internal safety stock is fixed and known for all products.

Concerning the picking activity, we suppose that the time it takes to pick a product from the forward area (respectively the reserve area) does not depend on the location of the product inside the forward area (respectively the reserve area) because products are typically picked during standard picking tours through the whole areas. Therefore, we won't make a distinction between the various locations inside the different areas. Nevertheless, the number of products that we can put in a location of the forward area will depend on the size or volume of that product. Each product can be picked either from the forward area or from the reserve area. If 
the product has been allocated to the forward area (respectively the reserve area) then all the picks have to be performed from the forward area (respectively the reserve area). Several units of a product can be picked in a single pick. The cost of picking is proportional to the number of picks.

Finally, concerning the external supply of the products, we assume that the warehouse manager want to use an inventory control policy based on continuous review policy (reorder point system). Therefore the order quantity is constant, the reorder point is constant, the delivery time is fixed and the demand of the various products during the supply lead time is probabilistic.

\subsection{Model}

The indexes used are $i: 1, \ldots, I$ to denote products and $j: 1, \ldots, J$ to denote a number of locations in the forward area.

Next, we describe the data and variables used in the model. For each element, we give the units of measure between brackets.

Data:

$\alpha_{i}$ : number of units of product $i$ that can be stored in a single location of the forward area.[units]

$\operatorname{CostRepA}$ : cost of advance replenishment. [euros/replenishment]

CostRepC : cost of concurrent replenishment. [euros/replenishment]

PickCostF : picking cost in the forward area.[euros/pick]

PickCostR : picking cost in the reserve area.[euros/pick]

$S S I$ : internal safety stock for products in the forward area which are replenished through the reserve area. [units]

$\operatorname{Cost} R$ : reception cost for the reserve area. [euros/reception]

Cost $F$ : reception cost for the forward area. [euros/reception]

CostCar : inventory Carrying cost [euros/units/picking period]

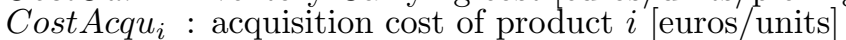

CostShort : shortage cost [euros/units]

CostCapasupp : additional capacity cost [euros/units]

$L$ : supply lead time [picking periods]

CapaF : capacity of the forward area.[locations]

CapaR : capacity of the reserve area.[units]

$U_{i}$ : random variable representing the demand of product $i$ during one picking period with expected value $E\left[U_{i}\right][$ units $]$

$d_{i}$ : random variable representing the demand of product $i$ during the supply lead time.[units]

$\sigma_{i}^{L}$ : standard deviation of demand of product $i$ during the supply lead time[units]

$\mu_{i}^{L}$ : average demand of product $i$ during the supply lead time[units]

$p_{i}$ : random variable representing the number of picks of product $i$ per picking $\operatorname{period}[$ picks $]$

$\delta_{i j}$ : expected number of concurrents replenishments of product $i$ per picking period, if $j$ locations are allocated to product $i$ in the forward area. Then $\delta_{i j}$ can be computed as $\delta_{i j}=\sum_{s=1}^{\infty} P\left(U_{i} \geq s\left(j \alpha_{i}-S S I\right)\right.$ because there is one concurrent replenishment each time that $\left(j \alpha_{i}-S S I\right)$ units of products have been picked. 
$u_{i j}$ : Using the definition of variable $\delta_{i j}$, we define $u_{i j}=\delta_{i j}-\delta_{i j-1}$

Variables:

$$
\begin{gathered}
x_{i, j}= \begin{cases}1 & \text { if the product } i \text { is supplied to the reserve area, picked } \\
\text { from the forward area and if } j \text { locations at least are } & \text { allocated to product } i \text { in the forward area } \\
0 & \text { otherwise }\end{cases} \\
y_{i}= \begin{cases}1 & \text { if the product } i \text { is supplied directly to the forward area } \\
& \text { from the suppliers and picked from the forward area only } \\
0 & \text { otherwise }\end{cases} \\
z_{i}= \begin{cases}1 & \text { if the product } i \text { is assigned to the reserve area and picked } \\
0 & \text { from the reserve area only }\end{cases}
\end{gathered}
$$

Capasupp $=$ number of external storage location rented [units]. (These are identical to the location in the reserve area)

$Q_{i}=$ replenishment quantity of product $i$ [units]

$r_{i}=$ reorder point of product $i$ [units]

Before stating the objective function, note that $x_{i j}$ have been chosen to be binary variables instead of integer variables because we believe that we get a stronger formulation. 
The objective function is the expected warehousing and inventory costs per picking period and is defined as follows:

$$
\begin{aligned}
& \min \sum_{i}^{I} \operatorname{CostRepA} \times x_{i 1} \\
& +\sum_{i}^{I} \sum_{j}^{J} \operatorname{CostRep} C \times x_{i j} \times u i j \\
& +\sum_{i=1}^{I} \operatorname{CostR} \times z_{i} \times \frac{E\left(U_{i}\right)}{Q_{i}}+\sum_{i=1}^{I} \operatorname{Cost} R \times x_{i 1} \times \frac{E\left(U_{i}\right)}{Q_{i}}+\sum_{i=1}^{I} \operatorname{CostF} \times y_{i} \times \frac{E\left(U_{i}\right)}{Q_{i}} \\
& +\sum_{i}^{I} \operatorname{PickCostF} \times E\left(p_{i}\right) \times\left(x_{i 1}+y_{i}\right) \\
& +\sum_{i}^{I} \operatorname{PickCostR} \times E\left(p_{i}\right) \times z_{i} \\
& +\operatorname{CostCapasupp} \times \operatorname{Capasupp} \\
& +\sum_{i}^{I} \operatorname{CostCar} \times\left(\frac{Q_{i}}{2}+r_{i}-\mu_{i}^{L}\right) \\
& +\sum_{i}^{I} \operatorname{CostAcqu} \times\left(\frac{E\left(U_{i}\right)}{Q_{i}}\right) \times Q_{i} \\
& +\sum_{i}^{I} \operatorname{CostShort} \times\left(\frac{E\left(U_{i}\right)}{Q_{i}}\right) \times \int_{r_{i}}^{\infty}\left(d_{i}-r_{i}\right) f\left(d_{i}\right) d d_{i}
\end{aligned}
$$

Concerning the warehouse costs, following our assumptions, we have taken into account the cost of advance replenishment of the forward area (1) and the cost of concurrent replenishment of the forward area (2). The cost of advance replenishments of product $i$ occurs once per picking period if product $i$ is assigned to the forward area (i.e, if $x_{i 1}=1$ ). The cost of concurrent replenishment depends on the number of concurrent replenishments which occur during the picking period. We have used the definition of $u_{i j}$ to obtain the concurrent replenishment cost as expressed in (2). The warehouse cost contains also picking cost in the forward area (4) (respectively the reserve area (5)). The rental cost of the additional storage capacity is expressed in (6).

The traditional inventory costs are composed of inventory carrying cost (7), acquisition cost (8) and shortage cost (9). We have also reception costs as defined in (3). 
Constraints :

$$
\begin{aligned}
& x_{i j} \leq x_{i j-1} \quad \forall i, j: j \geq 2 \\
& \sum_{i=1}^{I}\left[\left(\sum_{j=1}^{J} x_{i j}\right)+\left(\frac{Q_{i}+r_{i}-\mu_{i}^{L}}{\alpha_{i}}\right) y_{i}\right] \leq \text { CapaF } \\
& \sum_{i=1}^{I}\left[\left(\frac{Q_{i}}{2}+r_{i}-\mu_{i}^{L}\right) z_{i}+\left(\frac{Q_{i}}{2}+r_{i}-\mu_{i}^{L}\right) x_{i 1}-\sum_{j=1}^{J} \alpha_{i} x_{i j}\right] \leq \text { CapaR }+ \text { Capasupp } \\
& \sum_{i=1}^{I}\left[\left(Q_{i}+r_{i}-\mu_{i}^{L}\right) z_{i}+\left(Q_{i}+r_{i}-\mu_{i}^{L}\right) x_{i 1}-\sum_{j=1}^{J} \alpha_{i} x_{i j}\right] \leq \text { CapaR }+ \text { Capasupp } \\
& \sum_{i}^{I}\left(x_{i 1}+z_{i}+y_{i}\right)=1 \\
& \text { Capasupp } \geq 0 \\
& x_{i j}, y_{i}, z_{i}, Q_{i}, r_{i} \geq 0
\end{aligned}
$$

There are sequencing constraints (10) specifying that a $j^{\text {th }}$ location can be assigned to product $i$ only if $j-1$ locations have already been assigned. The number of products stored in the different areas (forward and reserve area) must not exceed the total amount of space available and depends on the storage policy: (11) for the dedicated storage in the forward area, (12) in case of random storage policy in the reserve area and (13) in case of dedicated storage policy in the reserve area. So depending on the policy only one constraint in (12) or (13) should be active. In addition, following the assumptions, the product can only follow one route in the warehouse (14). Finally, all the variables must be non negative(15)(16).

\section{Methodology}

The global model composed of the warehouse and the inventory decisions and constraints presented in Section 3.3 is a mixed integer non linear model. Given the complexity of solving this model to optimality, our aim is to find a procedure to solve heuristically this model in order to integrate decisions concerning the inventory and warehouse fields. We propose two heuristics methods to solve this problem offering different levels of decisions integration. The first method is a heuristic sequential solution procedure. The second method gives a higher level of integration and is similar to the method used in the iterative procedure proposed by C.J. Vidal and M. Goetschalchx [15] for solving bilinear models.

\subsection{Heuristic Sequential Solution}

In order to solve the model, we solve sequentially the inventory model then the warehouse model. Firstly, we solve a relaxation of the inventory model then the 
solution obtained for the inventory variables will be fixed and used to solve the warehouse model.

The inventory sub model (i.e., the original model without costs and constraints related to the warehouse problem) is the multi-item inventory control model with two capacity constraints ${ }^{1}$ defined by the minimization of inventory costs (reception inventory, carrying, shortage costs) under inventory and storage capacity constraints. The formulation of the inventory sub model is therefore:

$$
\begin{aligned}
\min & \sum_{i}^{I} \operatorname{CostCar} \times\left(\frac{Q_{i}}{2}+r_{i}-\mu_{i}^{L}\right) \\
+ & \sum_{i}^{I} \operatorname{CostAcqu}_{i} \times\left(\frac{E\left(U_{i}\right)}{Q_{i}}\right) \times Q_{i} \\
+ & \sum_{i}^{I} \operatorname{CostShort} \times\left(\frac{E\left(U_{i}\right)}{Q_{i}}\right) \times \int_{r_{i}}^{\infty}\left(d_{i}-r_{i}\right) f\left(d_{i}\right) d d_{i} \\
+ & \sum_{i=1}^{I} \operatorname{CostR} \times z_{i} \times \frac{E\left(U_{i}\right)}{Q_{i}}+\sum_{i=1}^{I} \operatorname{CostR} \times x_{i 1} \times \frac{E\left(U_{i}\right)}{Q_{i}}+\sum_{i=1}^{I} \operatorname{CostF} \times y_{i} \times \frac{E\left(U_{i}\right)}{Q_{i}} \\
+ & \text { CostCapasupp } \times \text { Capasupp }
\end{aligned}
$$

under the constraints

$$
\begin{aligned}
& \sum_{i=1}^{I}\left[\left(\sum_{j=1}^{J} x_{i j}\right)+\left(\frac{Q_{i}+r_{i}-\mu_{i}^{L}}{\alpha_{i}}\right) y_{i}\right] \leq \text { CapaF } \\
& \sum_{i=1}^{I}\left[\left(\frac{Q_{i}}{2}+r_{i}-\mu_{i}^{L}\right) z_{i}+\left(\frac{Q_{i}}{2}+r_{i}-\mu_{i}^{L}\right) x_{i 1}-\sum_{j=1}^{J} \alpha_{i} x_{i j}\right] \leq \text { CapaR }+ \text { Capasupp } \\
& \text { Capasupp } \geq 0 \\
& x_{i j}, y_{i}, z_{i}, Q_{i}, r_{i} \geq 0 \quad \forall i, j
\end{aligned}
$$

This is a non linear mixed integer model where the warehouse variables still appear in order to model the ordering/reception costs and capacity constraints. To render this model independent of the warehouse decisions variables, we will perform a relaxation and an approximation.

First of all we will approximate the objective function. The reception cost, which depends on the routes taken by the products, will be approximated by the following

\footnotetext{
${ }^{1}$ the constraint concerning the storage capacity of the reserve area depends on the storage policy of the reserve. We will develop in this section the methodology concerning the random storage policy. The methodology is easily adaptable in case of dedicated storage policy.
} 


$$
\sum_{i=1}^{I} \operatorname{Cost} \operatorname{Recp} \times \frac{E\left(U_{i}\right)}{Q_{i}}
$$

where CostRecp is the cost of reception which is independent on the route taken by the product and is defined as an average of the historical reserve and forward reception cost.

Secondly, we will approximate the capacity constraints (reserve and forward constraints). By this, we mean that instead of having two capacity constraints for the different areas in the warehouse, we will consider only one global capacity constraint for the entire warehouse. This global capacity constraint is the aggregation of the forward and the reserve capacity constraint, and is defined as follows :

$$
\sum_{i=1}^{I}\left(Q_{i}+r_{i}-\mu_{i}^{L}\right) \leq \text { Capa }+ \text { Capasupp }
$$

The new value Capa is the global aggregated warehouse capacity and is defined as the sum of $\bar{\alpha} C a p a F$ and $C a p a R$, where $\bar{\alpha}$ is the average historical number of products in one location of the forward area.

The objective function so obtained is independent on the routes taken by the various products. Consequently, the objective function is independent of the warehouse decisions taken.

The global capacity constraint is also independent of the routes taken by the different products in the warehouse. Nevertheless, the ordering quantity and reorder point of each product will be dependent on the amount of space globally available in the warehouse but not on the size of the different areas in the warehouse, the number of locations allocated to each product in the forward area and on the routes of the various products. This inventory model is therefore integrating a decision from inventory and warehouse fields (through the global capacity constraint).

By dualizing the global capacity constraint with multiplier $\lambda$ and the additional capacity non-negativity constraint with multiplier $\mu$, we obtain the lagrangian of this multi product inventory model with three unknown elements, $Q_{i}, r_{i}$ for all $\mathrm{i}=1 . . \mathrm{I}$ and CapaSupp and no constraint: 


$$
\begin{aligned}
L(\lambda, \mu)=\min & \sum_{i}^{I} \operatorname{CostCar} \times\left(\frac{Q_{i}}{2}+r_{i}-\mu_{i}^{L}\right) \\
+ & \sum_{i}^{I} \operatorname{CostAcqu}_{i} \times\left(\frac{E\left(U_{i}\right)}{Q_{i}}\right) \times Q_{i} \\
+ & \sum_{i}^{I} \text { CostShort } \times\left(\frac{E\left(U_{i}\right)}{Q_{i}}\right) \times \int_{r_{i}}^{\infty}\left(d_{i}-r_{i}\right) f\left(d_{i}\right) d d_{i} \\
+ & \sum_{i=1}^{I} \text { CostRecp } \times \frac{E\left(U_{i}\right)}{Q_{i}} \\
+ & \text { CostCapasupp } \times \text { Capasupp } \\
- & \lambda \times\left(\text { Capa }+ \text { Capasupp }-\left(\sum_{i=1}^{I}\left(Q_{i}+r_{i}-\mu_{i}^{L}\right)\right)\right) \\
& \quad \mu \times \text { Capasupp }
\end{aligned}
$$

The first order necessary conditions are used to derive the optimal value for the ordering quantity $\left(Q_{i}\right)$, the reorder point $\left(r_{i}\right)$ for all $i=1 . . I$ and the additional capacity (Capasupp) for fix $\lambda$ and $\mu[8]$. The standard necessary conditions for optimality give the following results ${ }^{2}$ :

$$
\begin{aligned}
& \overline{Q_{i}}=\sqrt{\frac{2 \times E\left(U_{i}\right) \times\left(\text { CostRecp }+ \text { CostShort } \times \int_{r_{i}}^{\infty}\left(d_{i}-\overline{r_{i}}\right) f\left(d_{i}\right) d d_{i}\right)}{(\text { CostCar }+2 \times \bar{\lambda})}} \\
& \operatorname{Prob}\left(d_{i} \geq \overline{r_{i}}\right)=\frac{\overline{Q_{i}} \times(\text { CostCar }+\bar{\lambda})}{\text { CostShort } \times E\left(U_{i}\right)} \\
& \text { CostCapasupp }-\bar{\lambda}-\bar{\mu}=0
\end{aligned}
$$

We omit the non negativity constraint on $Q_{i}$ and $r_{i}$ because they are satisfied by the first order condition. The complementary slackness and feasibility conditions are used to determine the optimal value of the additional capacity (Capasupp) and the Lagrangian multipliers $(\lambda, \mu)$ :

\footnotetext{
${ }^{2}$ In the rest of the paper, for notational convenience, the optimal value of the variables will be indicated by an upper bar
} 


$$
\begin{aligned}
& \bar{\lambda} \times\left(\text { Capa }+\overline{\text { Capasupp }}-\left(\sum_{i=1}^{I}\left(\overline{Q_{i}}+\overline{r_{i}}-\mu_{i}^{L}\right)\right)\right)=0 \\
& \bar{\mu} \times \overline{\text { Capasupp }}=0 \\
& \sum_{i=1}^{I}\left(\overline{Q_{i}}+\overline{r_{i}}-\mu_{i}^{L}\right) \leq \text { Capa }+\overline{\text { Capasupp }} \\
& \overline{\text { Capasupp }} \geq 0 \\
& \bar{\mu} \geq 0 \\
& \bar{\lambda} \geq 0
\end{aligned}
$$

By combining the necessary optimality condition (19), the complementary slackness condition (21) and the feasibility condition (24) we obtain :

$$
\begin{aligned}
& (\text { CostCapasupp }-\bar{\lambda}) \times \overline{\text { Capasupp }}=0 \\
& \bar{\lambda} \leq \text { CostCapasupp }
\end{aligned}
$$

which replaces (19), (21) and (24).

The resulting first order necessary conditions are defined as :

$$
\begin{aligned}
& \overline{Q_{i}}=\sqrt{\frac{2 \times E\left(U_{i}\right) \times\left(\text { CostRecp }+ \text { CostShort } \times \int_{r_{i}}^{\infty}\left(d_{i}-\overline{r_{i}}\right) f\left(d_{i}\right) d d_{i}\right)}{(\text { CostCar }+2 \times \bar{\lambda})}} \\
& \operatorname{Prob}\left(d_{i} \geq \overline{r_{i}}\right)=\frac{\overline{Q_{i}} \times(\text { CostCar }+\bar{\lambda})}{\text { CostShort } \times E\left(U_{i}\right)} \\
& \bar{\lambda} \times\left(\text { Capa }+\overline{\text { Capasupp }}-\left(\sum_{i=1}^{I}\left(\overline{Q_{i}}+\overline{r_{i}}-\mu_{i}^{L}\right)\right)\right)=0 \\
& \sum_{i=1}^{I}\left(\overline{Q_{i}}+\overline{r_{i}}-\mu_{i}^{L}\right) \leq \text { Capa }+\overline{\text { Capasupp }} \\
& 0 \leq \bar{\lambda} \leq \text { CostCapasupp } \\
& \overline{\text { Capasupp } \geq 0} \\
& (\text { CostCapasupp }-\bar{\lambda}) \times \overline{\text { Capasupp }}=0
\end{aligned}
$$

To find all possible solution to (28) - (34), we must distinguish three possible cases : 
1. $\bar{\lambda}=0$

Following (34), the value of the additional capacity ( $\overline{\text { Capasupp }}$ ) must be equal to zero.

The optimal order quantity and reorder point can be calculated by equations (28) and (29).

The value of $Q_{i}$ and $r_{i}$ for all $i=1 . . I$ can then be used to see if (31) is satisfied (i.e. if there is a solution with $\overline{\text { Capasupp }}=0$ and the constraint satisfied). If the constraint is not satisfied then there is no solution with $\bar{\lambda}=0$. If the constraint is satisfied, we have a solution to the lagrangian.

2. $\bar{\lambda}>0$

Following (30), the capacity constraint is saturated.

Following (32) and (34), we must distinguish two different cases.

(a) $\bar{\lambda}=$ CostCapasupp

The optimal order quantity and reorder point can be calculated by equations (28) and (29).

From (34), capasupp $\geq 0$ and can be calculated with (31)(taking into account the fact that the constraint is saturated). If the value of $\overline{\text { Capasupp }}$ obtained is greater or equal to zero then we have a feasible solution otherwise we have no solution.

(b) $0<\bar{\lambda}<$ CostCapasupp

From equation (34), the value of the additional capacity $\overline{\text { Capasupp }}$ is equal to zero.

The optimal value of the lagrangian multiplier can be calculated by solving a system composed of three equations with three unknown elements. Indeed, we obtain a lagrangian composed of three unknown elements $\left(Q_{i}, r_{i}\right.$ and $\left.\lambda\right)$. In addition, we know that the global capacity constraint is binding. In this case, we can derive the three necessary conditions for optimality $([8],[11])$ and calculate the value of the three unknown elements.

The first order necessary conditions are as follows:

$$
\begin{aligned}
& \overline{Q_{i}}=\sqrt{\frac{2 \times E\left(U_{i}\right) \times\left(\text { CostRecp }+ \text { CostShort } \times \int_{r_{i}}^{\infty}\left(d_{i}-r_{i}\right) f\left(d_{i}\right) d d_{i}\right)}{(\operatorname{CostCar}+2 \times \bar{\lambda})}} \\
& \operatorname{Prob}\left(d_{i} \geq \overline{r_{i}}\right)=\frac{\overline{Q_{i}} \times(\text { CostCar }+\bar{\lambda})}{\text { CostShort } \times E\left(U_{i}\right)} \\
& \sum_{i=1}^{I}\left(\overline{Q_{i}}+\overline{r_{i}}-\mu_{i}^{L}\right)=\text { Capa }
\end{aligned}
$$

Those three possible solution cases will be analyzed, a possible solution will be calculated and the best one will be selected(i.e. the one which minimize the most the objective function of the first subproblem). 
In each of the possible solution cases presented above, the necessary conditions for optimality $(28,29)$ must be calculated for fixed values of $\bar{\lambda}$. But as the order quantity depends on the reorder point and conversely, an iterative procedure is used to find the optimal value of the two unknown elements. The iterative procedure will stop when the value for the variables from one iteration to the other is relatively stable. In case of 2.(b), we must in addition find the value $\bar{\lambda}$ such that (35) is satisfied. Therefore, we need to update $\bar{\lambda}$, resolve (28)-(29) until (35) is satisfied.

When the optimal solution of the inventory model is obtained, the optimal order and reorder quantity are used to solve the warehouse model. The resulting warehouse model (where the value of the inventory variables $\left(Q_{i}, r_{i}\right.$ for all $i=1 . . I$ ) are fixed based on the solution of the inventory model with one capacity constraint) is a mixed integer problem which is solved using a Branch\&Bound procedure. In the warehouse model, the two capacity constraints are taken into account in order to obtain a feasible solution to the warehouse model and the optimal value of the additional capacity (CapaSupp) is reoptimized. The warehouse model is defined as follows:

$$
\begin{aligned}
& \min \sum_{i}^{I} \operatorname{CostRepA} \times x_{i 1} \\
& +\sum_{i}^{I} \sum_{j}^{J} \operatorname{CostRepC} \times x_{i j} \times u i j \\
& +\sum_{i=1}^{I} \operatorname{CostR} \times z_{i} \times \frac{E\left(U_{i}\right)}{\overline{Q_{i}}}+\sum_{i=1}^{I} \operatorname{CostR} \times x_{i 1} \times \frac{E\left(U_{i}\right)}{\overline{Q_{i}}}+\sum_{i=1}^{I} \operatorname{Cost} F \times y_{i} \times \frac{E\left(U_{i}\right)}{\overline{Q_{i}}} \\
& +\sum_{i}^{I} \operatorname{PickCost} \times E\left(p_{i}\right) \times\left(x_{i 1}+y_{i}\right) \\
& +\sum_{i}^{I} \text { PickCostR } \times E\left(p_{i}\right) \times z_{i} \\
& + \text { CostCapasupp } \times \text { Capasupp }
\end{aligned}
$$

under the following constraints: 


$$
\begin{aligned}
& x_{i j} \leq x_{i j-1} \quad \forall i, j: j \geq 2 \\
& \sum_{i=1}^{I}\left[\left(\sum_{j=1}^{J} x_{i j}\right)+\left(\frac{\overline{Q_{i}}+\overline{r_{i}}-\mu_{i}^{L}}{\alpha_{i}}\right) y_{i}\right] \leq \text { CapaF } \\
& \sum_{i=1}^{I}\left[\left(\frac{\overline{Q_{i}}}{2}+\overline{r_{i}}-\mu_{i}^{L}\right) z_{i}+\left(\frac{\overline{Q_{i}}}{2}+\overline{r_{i}}-\mu_{i}^{L}\right) x_{i 1}-\sum_{j=1}^{J} \alpha_{i} x_{i j}\right] \leq \text { CapaR }+ \text { Capasupp } \\
& \sum_{i}^{I}\left(x_{i 1}+z_{i}+y_{i}\right)=1 \\
& \text { CapaSupp } \geq 0 \\
& x_{i j}, y_{i}, z_{i} \geq 0 \quad \forall i, j
\end{aligned}
$$

\subsection{Integrated Heuristic method}

According to C.J. Vidal and M. Goetschalchx [15], global optimization for bi-linear problems is only possible for small instances. Medium and large scale supply chain problems such as warehouse planning and inventory management problems need to be solved through a heuristic approach. They propose a heuristic based on an iterative solution of the two linear subproblems. We use the same heuristic approach to solve our non linear MIP model. We decompose the global model according to the different variables and we isolate two groups of variables: the inventory and the warehouse variables. Each of these groups of variables will define a subproblem.

The first subproblem will be composed of the inventory variables and constraints and the values of the warehouse variables will be fixed (by the value obtained at the previous iteration). Consequently, the ordering cost and the location of the products inside the warehouse is fixed by the value of the warehouse variables. We obtain a classical multi product inventory model with two capacity constraints for each area in the warehouse (forward and reserve area). The objective function of the first inventory subproblem is : 


$$
\begin{aligned}
& \min \sum_{i}^{I} \operatorname{CostCar} \times\left(\frac{Q_{i}}{2}+r_{i}-\mu_{i}^{L}\right) \\
& +\sum_{i}^{I} \operatorname{CostAcqu}_{i} \times\left(\frac{E\left(U_{i}\right)}{Q_{i}}\right) \times Q_{i} \\
& +\sum_{i}^{I} \operatorname{CostShort}\left(\frac{E\left(U_{i}\right)}{Q_{i}}\right) \int_{r_{i}}^{\infty}\left(d_{i}-r_{i}\right) f\left(d_{i}\right) d d_{i} \\
& +\sum_{i=1}^{I} \operatorname{CostR} \times \overline{z_{i}} \times \frac{E\left(U_{i}\right)}{Q_{i}}+\sum_{i=1}^{I} \operatorname{CostR} \times \overline{x_{i 1}} \times \frac{E\left(U_{i}\right)}{Q_{i}}+\sum_{i=1}^{I} \operatorname{CostF} \times \overline{y_{i}} \times \frac{E\left(U_{i}\right)}{Q_{i}} \\
& + \text { CostCapasupp } \times \text { Capasupp }
\end{aligned}
$$

Under the constraints :

$$
\begin{aligned}
& \sum_{i=1}^{I}\left[\left(\sum_{j=1}^{J} \overline{x_{i j}}\right)+\left(\frac{Q_{i}+r_{i}-\mu_{i}^{L}}{\alpha_{i}}\right) \overline{y_{i}}\right] \leq \text { CapaF } \\
& \sum_{i=1}^{I}\left[\left(\frac{Q_{i}}{2}+r_{i}-\mu_{i}^{L}\right) \overline{z_{i}}+\left(\frac{Q_{i}}{2}+r_{i}-\mu_{i}^{L}\right) \overline{x_{i 1}}-\sum_{j=1}^{J} \alpha_{i} \overline{x_{i j}}\right] \leq \text { CapaR }+ \text { Capasupp }
\end{aligned}
$$

Capasupp $\geq 0$

$Q_{i}, r_{i} \geq 0 \quad \forall i, j$

By dualizing the two capacity constraints with multipliers $\lambda^{F}$ (forward capacity constraint) and $\lambda^{R}$ (reserve capacity constraint) and the non-negativity additional capacity constraint with multiplier $\mu$, the lagrangian can be written as followed: 


$$
\begin{aligned}
& L\left(\lambda^{F}, \lambda^{R}, \mu\right)= \\
& \min \sum_{i}^{I} \operatorname{CostCar} \times\left(\frac{Q_{i}}{2}+r_{i}-\mu_{i}^{L}\right) \\
& +\sum_{i}^{I} \operatorname{CostAcqu}_{i} \times\left(\frac{E\left(U_{i}\right)}{Q_{i}}\right) \times Q_{i} \\
& +\sum_{i}^{I} \operatorname{CostShort}\left(\frac{E\left(U_{i}\right)}{Q_{i}}\right) \int_{r_{i}}^{\infty}\left(d_{i}-r_{i}\right) f\left(d_{i}\right) d d_{i} \\
& +\sum_{i=1}^{I} \operatorname{CostR} \times \overline{z_{i}} \times \frac{E\left(U_{i}\right)}{Q_{i}}+\sum_{i=1}^{I} \operatorname{CostR} \times \overline{x_{i 1}} \times \frac{E\left(U_{i}\right)}{Q_{i}}+\sum_{i=1}^{I} \operatorname{CostF} \times \overline{y_{i}} \times \frac{E\left(U_{i}\right)}{Q_{i}} \\
& + \text { CostCapasupp } \times \text { Capasupp } \\
& -\lambda^{F} \times\left(\text { CapaF }-\left[\sum_{i=1}^{I}\left[\left(\sum_{j=1}^{J} \overline{x_{i j}}\right)+\left(\frac{Q_{i}+r_{i}-\mu_{i}^{L}}{\alpha_{i}}\right) \overline{y_{i}}\right]\right]\right) \\
& -\lambda^{R} \times\left(\text { CapaR }+ \text { Capasupp }-\left[\sum_{i=1}^{I}\left[\left(\frac{Q_{i}}{2}+r_{i}-\mu_{i}^{L}\right) \overline{z_{i}}+\left(\frac{Q_{i}}{2}+r_{i}-\mu_{i}^{L}\right) \overline{x_{i 1}}-\sum_{j=1}^{J} \alpha_{i} \overline{x_{i j}}\right]\right]\right) \\
& -\mu \times \text { Capasupp }
\end{aligned}
$$

First of all, as we have done in the sequential heuristic solution procedure, the necessary optimality condition on the variable Capasupp and the complementary slackness and feasibility conditions on the additional capacity non-negativity constraint can be used to derive the different possible values of the variable Capasupp and the lagrangian multipliers $\mu$ and $\lambda^{R}$.

$$
\begin{aligned}
& \text { CostCapasupp }-\overline{\lambda^{R}}-\bar{\mu}=0 \\
& \bar{\mu} \times \overline{\text { Capasupp }}=0 \\
& \bar{\mu} \geq 0 \\
& \overline{\text { Capasupp }} \geq 0
\end{aligned}
$$

From the above equations, we can derive the following:

$$
\begin{aligned}
& \overline{\text { Capasupp }} \geq 0 \\
& \left(\text { CostCapasupp }-\overline{\lambda^{R}}\right) \times \overline{\text { Capasupp }}=0 \\
& 0 \leq \overline{\lambda^{R}} \leq \text { CostCapasupp }
\end{aligned}
$$

This system (41) and (42) gives the different possible value for $\lambda^{R}$ (and consequently $\mu$ ) and Capasupp which solve the lagrangian. We can then write the first order necessary optimality conditions defining the optimal order quantity and reorder point for each product for a fixed value of $\lambda^{R}$ and $\lambda^{F}$ : 
$\overline{Q_{i}}=\sqrt{\frac{2 \times E\left(U_{i}\right) \times\left(\operatorname{CostR} \times \overline{z_{i}}+\operatorname{Cost} R \times \overline{x_{i 1}}+\operatorname{CostF} \times \overline{y_{i}}+\operatorname{CostShort} \times E\left(U_{i}\right) \times \int_{r_{i}}^{\infty}\left(d_{i}-\overline{r_{i}}\right) f\left(d_{i}\right) d d_{i}\right.}{2 \times \overline{\frac{\lambda}{\alpha_{i}}} \times \overline{y_{i}}+2 \times \overline{\lambda^{R}} \times \overline{z_{i}}+2 \times \overline{\lambda^{R}} \times \overline{x_{i 1}}+\operatorname{CostCar}}}$

$\operatorname{prob}\left(d_{i} \geq \overline{r_{i}}\right)=\frac{\overline{Q_{i}}}{\text { CostShort } \times E\left(U_{i}\right)} \times\left(\operatorname{CostCar}+\frac{\overline{\lambda^{F}}}{\alpha_{i}} \times \overline{y_{i}}+\overline{\lambda^{R}} \times \overline{z_{i}}+\overline{\lambda^{R}} \times \overline{x_{i 1}}\right)$

In order to solve (40) - (44), we must distinguish three possible situations:

1. $\overline{\lambda^{R}}=0$

We obtain a lagrangian where one capacity constraint (forward capacity constraint) has been dualized. This lagrangian can be solved by the same methodology used in the sequential heuristic procedure.

2. $\overline{\lambda^{R}}>0$

(a) $\overline{\lambda^{R}}=$ CostCapasupp

As the value of $\overline{\lambda^{R}}$ is fixed, we obtain again a lagrangian with one capacity constraint (forward capacity constraint) which can be solved based on the sequential heuristic procedure.

(b) $0<\overline{\lambda^{R}}<$ CostCapasupp

The optimal value of the lagrangian multipliers $\left(\overline{\lambda^{R}}, \overline{\lambda^{F}}\right)$ will be determined by lagrangian relaxation where the two capacity constraints (forward and reserve constraints) will be dualized. The optimal value of the two lagrangian multipliers will be found by applying the subgradient optimization algorithm on the lagrangian dual. The resulting lagrangian dual is as follows:

$$
W_{L D}=\operatorname{Max}\left\{L\left(\lambda^{F}, \lambda^{R}\right): \lambda^{F}, \lambda^{R} \geq 0\right\}
$$

Then, the optimal order quantity and reorder point will be calculated with the system (43) and (44) for fixed values of $\overline{\lambda^{R}}$ and $\overline{\lambda^{F}}$

We have decided that, due to the non monotonicity of the objective function, we will stop the subgradient optimization phase when we encounter ten iterations without an improvement in the solution obtained.

In the second subproblem, the warehouse variables will be optimized taking into account the warehouse capacity, allocation and the routing constraints while the values of the inventory variables will be fixed. The model obtained is a mixed integer problem where the reorder point and the ordering quantity are fixed (at 
the value obtained at the previous iteration). This problem is solved by Branch \& Bound. This mixed integer model is the same as the one used to solve the model with the sequential heuristic procedure.

Those two subproblems are solved iteratively (Figure 1), where the output of one of the subproblem will become the input of the other subproblem at the next iteration.

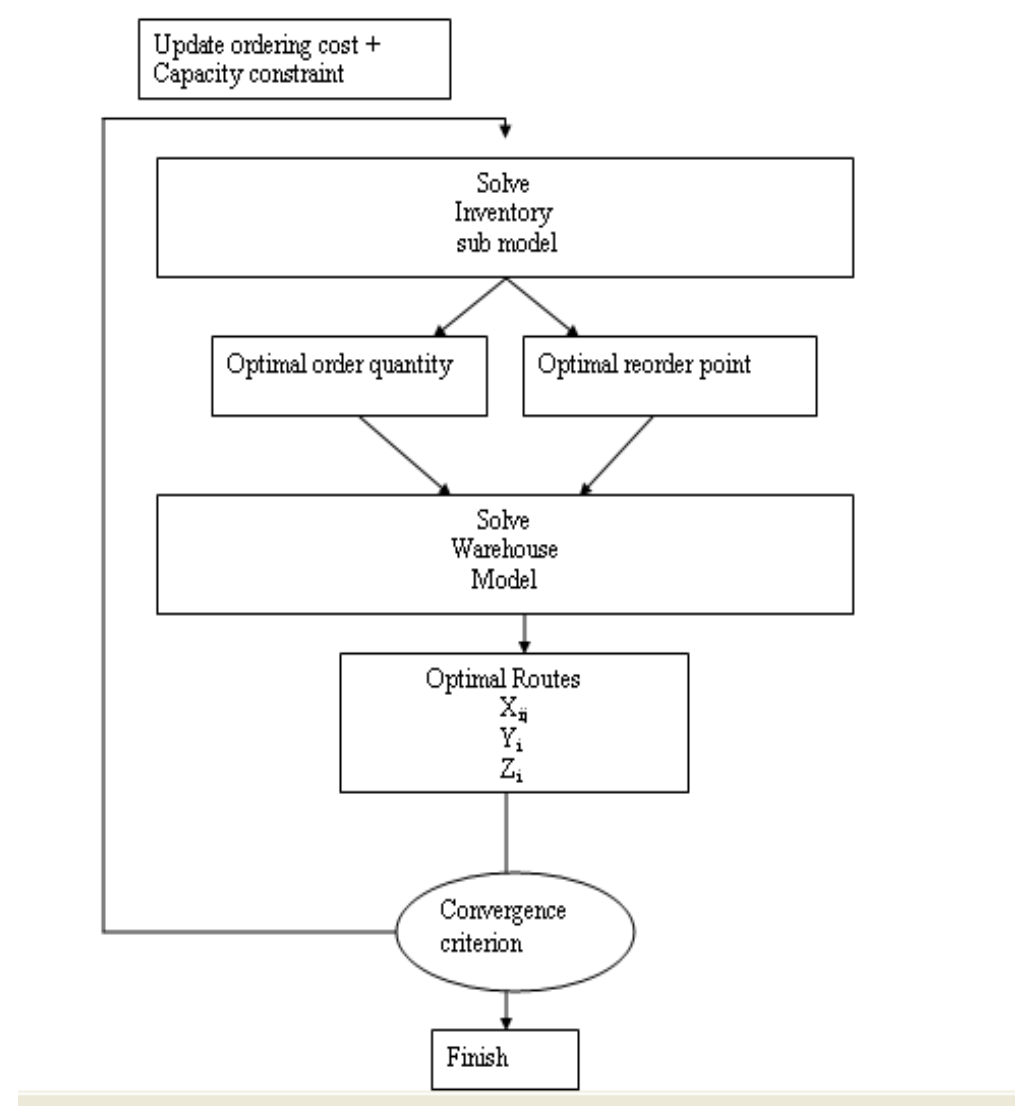

Figure 1: The iterative procedure in the integrated model

We decide to stop the iterative process after a limited number of iterations where the best inventory and warehouse cost has been recorded at each iteration. Indeed, this stopping criterion is based on two facts. First of all, we want to keep a reasonable computing time. Secondly, we have observed, in preliminary test, that the improvement in warehouse and inventory cost was occurring in the first steps of the iterative process.

This procedure offers a higher level of integration of warehouse and inventory decisions because we do not only take into account the size of the warehouse in 
the inventory model but also the size of the different areas in the warehouse, the routes taken by the products and the size of the location inside each areas of the warehouse.

\section{Computational results}

In order to present the value of integrating warehouse and inventory decisions, the different solution methods are tested on a real world database. The different methods tested differ according to their level of integration.

\section{$5.1 \quad$ Database}

The evaluation of the heuristics proposed in Section 4 will be realized through tests which will be performed on 400 products coming from real world data of the retail sector ${ }^{3}$. In order to be able to implement the heuristics, some information are needed concerning the products. Concerning the demands of the products, we have assumed that picking periods demand of product $i$ in the warehouse follows a normal distribution $\mathrm{N}\left(\mu_{i}, \sigma_{i}\right)$. This assumption was made because, in order to derive the demand probability distribution, we needed the histogram of the expeditions per picking period and this information was not available. In addition, those products are delivered regularly which supports the assumption.

Secondly, the inventory model that we have considered is a continuous review, multi-item reorder point with lost sales. This lost sales assumption is made because, in case of shortage, an urgent order is expedited from another warehouse (so the order is lost for the warehouse under study) in order to obtain a $100 \%$ service level.

The different costs composing the objective function were not available in the company. Those costs have been fixed according to the assumptions made in the model description ${ }^{4}$.

\subsection{Benchmark methods}

The different methods used and compared as benchmark are presented below in increasing level of integration (from left to right).

The first benchmark method is the one that most companies use today. In the first step, an uncapacited inventory model is solved for each item, where the ordering quantity and the reorder point is calculated without taking into account the size of the warehouse, the size of the different areas in the warehouse and the routes of the products. The inventory decisions are taken independently of the warehouse decisions, based on ordering and inventory costs trade-offs.

\footnotetext{
${ }^{3}$ for more information on the dataset see the appendix

${ }^{4}$ a sensitivity analysis is performed in Section 5.4 in order to analyse the impact of changes in the objective function costs
} 


\begin{tabular}{|c|c|c|c|}
\hline & $\begin{array}{l}\text { Uncapacited } \\
\text { method }\end{array}$ & $\begin{array}{l}\text { Heuristic sequential } \\
\text { method }\end{array}$ & $\begin{array}{c}\text { Integrated } \\
\text { method }\end{array}$ \\
\hline $\begin{array}{l}\text { inventory } \\
\text { models }\end{array}$ & $\begin{array}{c}\text { Multi product } \\
\text { inventory control } \\
\text { model without } \\
\text { capacity constraint }\end{array}$ & $\begin{array}{c}\text { Multi product } \\
\text { inventory control } \\
\text { model with } \\
\text { one capacity constraint }\end{array}$ & \multirow{2}{*}{$\begin{array}{c}\text { Multi product } \\
\text { inventory control } \\
\text { model with } \\
\text { two capacity } \\
\text { constraints } \\
\text { MILP }\end{array}$} \\
\hline $\begin{array}{l}\text { warehouse } \\
\text { models }\end{array}$ & MILP & MILP & \\
\hline
\end{tabular}

Table 1: Benchmark models

Once the uncapacited multi items inventory control model is solved, the warehouse model is solved based on the value of the inventory variables found. This warehouse model is the same as the one use for the sequential heuristic procedure and the integrated method.

The other two benchmark methods have been presented in the Section 4 .

\subsection{Description of the computational results}

For the presentation of the results obtained with the various methods described in Section 5.2, we give the difference in cost (expressed in percentage) when we use a more integrated method. For ease of presentation, we are going to introduce two new definitions:

- First integration savings

The improvement obtained in the inventory and warehouse costs when we use, on the same dataset, with the same capacity and storage policy, the heuristic sequential procedure instead of the uncapacited procedure. This improvement will be expressed in percentage. A positive value for the improvement means an improvement in cost (decrease in cost) when using the sequential procedure instead of the uncapacited procedure.

- Second integration savings

The improvement obtained in the inventory and warehouse costs when we use, on the same dataset, with the same capacity and storage policy, the integrated procedure instead of the uncapacited procedure. This improvement will be expressed in percentage. A positive value for the improvement means an improvement in cost (decrease in cost) when using the integrated procedure instead of the uncapacited procedure. 


\subsubsection{Unlimited reserve capacity}

When there is unlimited capacity in the warehouse (unlimited reserve area, but limited size of the forward area), the sequential heuristic procedure and the uncapacited method give, as expected, the same result for the inventory and the warehouse decisions. Indeed, the only difference between the two models is that the sequential heuristic procedure takes into account a global capacity constraint which is redundant when there is enough capacity in the warehouse. We can conclude that the first integration gives $0 \%$ improvement in cost. The only improvement in warehouse and inventory cost is observed when the integrated model is used. In the integrated model, it is still possible to optimize the amount of products which can be stored in a location of the warehouse area and optimize the routes taken by the various products. Consequently, the available space in the warehouse is used more appropriately. Therefore, tables 2 and 3 show the results for the second integration.

\begin{tabular}{|c|c|c|c|c|}
\hline \multicolumn{5}{|c|}{ Warehouse Cost Savings (\%) } \\
\hline & Replenishment & $\begin{array}{c}\text { Reserve } \\
\text { picking } \\
\text { \&reception } \\
\text { cost }\end{array}$ & $\begin{array}{c}\text { Forward } \\
\text { picking } \\
\text { \&reception } \\
\text { cost }\end{array}$ & $\begin{array}{c}\text { Total } \\
\text { warehouse } \\
\text { cost }\end{array}$ \\
\hline $\begin{array}{c}\text { Second } \\
\text { Integration }\end{array}$ & 0.877 & -0.584 & 1.960 & 0.989 \\
\hline
\end{tabular}

Table 2: Unlimited capacity warehouse results (expressed in percentage).

\begin{tabular}{|c|c|c|c|c|}
\hline \multicolumn{5}{|c|}{ Inventory Cost Savings (\%) } \\
\hline & $\begin{array}{c}\text { Reception } \\
\text { cost }\end{array}$ & $\begin{array}{c}\text { Carrying } \\
\text { cost }\end{array}$ & $\begin{array}{c}\text { Shortage } \\
\text { cost }\end{array}$ & $\begin{array}{c}\text { Total inventory } \\
\text { cost }\end{array}$ \\
\hline $\begin{array}{c}\text { Second } \\
\text { Integration }\end{array}$ & 9.460 & -0.001 & -0.166 & 0.027 \\
\hline
\end{tabular}

Table 3: Unlimited capacity inventory results(expressed in percentage).

With the integrated model, the optimal order quantities have increased compared with the result obtained with the heuristic sequential procedure. This implies a decrease in the reception cost and an increase in the storage cost. Concerning the shortage cost, an increase in the order quantity implies a decrease in the number of replenishment cycles. Nevertheless, this decrease is compensated by a decrease in the safety factor which increases the expected shortage per replenishment cycle. The decrease of the reception cost can also be explained through the reoptimiza- 
tion of the routes in the integrated procedure. The increase in the order quantities implies that some products, which were, with the heuristic sequential procedure, supplied directly to the forward area, must be supplied through the reserve area because there is not enough space anymore. Consequently, more product are picked from the reserve area which decreases the replenishment cost and decreases the forward reception and picking cost.

The amount of space consumed in the reserve area has slightly increased. This increase is mainly due to the shift in routes.

The forward capacity is used totally and better with the integrated procedure because each location in this area is filled totally.

\subsubsection{Limited warehouse capacity}

In the case of limited warehouse capacity (in the forward and in the reserve area), savings can be obtained by using the first integration and the second integration.

\begin{tabular}{|c|c|c|c|c|c|}
\hline & \multicolumn{5}{|c|}{ Warehouse Cost Savings (\%) } \\
\hline & Replenishment & $\begin{array}{c}\text { Reserve } \\
\text { picking } \\
\text { \&reception } \\
\text { cost }\end{array}$ & $\begin{array}{c}\text { Forward } \\
\text { picking } \\
\text { \&reception } \\
\text { cost }\end{array}$ & $\begin{array}{c}\text { additional } \\
\text { capacity } \\
\text { cost }\end{array}$ & $\begin{array}{c}\text { Total } \\
\text { warehouse } \\
\text { cost }\end{array}$ \\
\hline $\begin{array}{c}\text { First } \\
\text { integration }\end{array}$ & 18.056 & -3.496 & -15.229 & 100.000 & 57.946 \\
\hline $\begin{array}{c}\text { Second } \\
\text { integration }\end{array}$ & 15.641 & 2.897 & -8.852 & 100.000 & 59.325 \\
\hline
\end{tabular}

Table 4: Limited capacity warehouse results (expressed in percentage).

\begin{tabular}{|c|c|c|c|c|}
\hline & \multicolumn{4}{|c|}{ Inventory Cost Savings (\%) } \\
\hline & $\begin{array}{c}\text { Reception } \\
\text { Cost }\end{array}$ & $\begin{array}{c}\text { Carrying } \\
\text { Cost }\end{array}$ & $\begin{array}{c}\text { Shortage } \\
\text { capacity Cost }\end{array}$ & $\begin{array}{c}\text { Total inventory } \\
\text { Cost }\end{array}$ \\
\hline $\begin{array}{c}\text { First } \\
\text { integration }\end{array}$ & -85.433 & 13.128 & -96.116 & 1.282 \\
\hline $\begin{array}{c}\text { Second } \\
\text { integration }\end{array}$ & -29.549 & 10.161 & -65.176 & 4.767 \\
\hline
\end{tabular}

Table 5: Limited capacity inventory results (expressed in percentage). 


\section{The improvement obtained by the first integration}

As there is limited space in the reserve area, we can observe a reduction in the order quantity when the sequential heuristic procedure is used. We have shown that the global capacity constraint used in this solution method is associated to a lagrangian multiplier (see Section 4.1) which can be interpreted as an implicit storage cost. Indeed, when there is not enough capacity in the warehouse, the carrying cost increases due to this lagrange multiplier (see equation 28 in Section 4.1) which results in a decrease in the order quantity. Firstly, this order quantity reduction implies higher reception and shortage cost. Nevertheless, this increase in reception and shortage cost is compensated by the decrease in carrying cost and mostly the decrease of additional capacity cost. Also observed that the carrying becomes so expensive (the lagrange multiplier increase because of limited capacity) that it is more interesting to have higher shortage cost (reducing service level).

Secondly, this reduction in the order quantity implies that some product could be supplied directly in the forward area (when the reduction in the order quantity allows it) instead of being supplied through the reserve area. Consequently, we can observe a change in the routes, which combined with the reduction in the order quantity, allows to decrease drastically the cost of renting additional capacity and replenishment cost. Concerning the picking cost, there is an increase in the reserve picking cost and a decrease in the forward picking cost which is due to the reoptimization of the routes.

The reduction in the order quantity, when using the heuristic sequential procedure, is drastic. This can be explained by the type of relaxation used for the inventory model (see 4.1). Indeed, the global capacity constraint used in this method was based on a dedicated storage policy which is more restrictive than the real capacity constraints. This implies that the storage capacity is unadequatly used.

\section{The improvement obtained by the second integration.}

With the integrated procedure, the quantity allocated to each location in the forward area is optimized. This results in a decrease in the order quantity compared to the uncapacited method which results in an increase in the reception cost and shortage cost and a decrease in the carrying cost. Nevertheless, this decrease in the order quantity is less important than the one obtained with the first integration because the capacity constraints are more adequately represented in the integrated method. Consequently, the available space in the warehouse is more adequately used.

Concerning the routes taken by the various products, this change in the order quantity allows to fill in better the locations of the forward area for certain products. For other product, this increase in the ordered quantity does not justify a location in the forward area anymore which frees some place for other product which fill in better the space. This optimization of space involves a change of routes which implies that there is more direct reception through the forward area and less reception through the reserve area. Consequently, 
the replenishment cost decreases compared to the uncapacited method (introduced in Section 5.2).

\subsubsection{Value of integration}

\begin{tabular}{c|c|c} 
& Limited Reserve Capacity & Unlimited Reserve Capacity \\
\hline $\begin{array}{c}\text { First } \\
\text { integration }\end{array}$ & 8.817 & 0 \\
\hline $\begin{array}{c}\text { Second } \\
\text { integration }\end{array}$ & 12.022 & 0.079 \\
\hline
\end{tabular}

Table 6: Total savings (in percentage) with limited and unlimited capacity.

Table 6 summarizes the percentage of total savings which can be obtained by integrating more decisions of the warehouse and inventory fields.

The amount of savings which can be achieved depends on the capacity available in the warehouse.

When there is enough capacity, only the integrated model allows one to improve the inventory and warehouse costs due to a better management of the different locations in the forward area. This involves a reoptimization of the routes. Nevertheless, the amount of savings realized is relatively small compared to the savings obtained in the case of limited capacity.

When the capacity available in the warehouse is limited, the major part of the savings is incurred by using the heuristic sequential procedure. This is mainly due to the decrease in additional storage capacity rented. With the integrated method, space is utilized better than when the heuristic sequential method is used due to the fact that the capacity constraint are better represented and taken into account.

\subsection{Sensitivity analysis}

The computational tests have been performed without having the real value of the different cost coefficients composing the objective function. In addition, in business, changes in the objective function cost coefficients can occur. For example, changes in the productivity of the pickers which will influence the picking cost or changes in the carrying cost due to changes in the value of the product [12] . Therefore, entreprises may be interested in knowing if those changes will have an impact on the optimal inventory and warehouse configuration (i.e optimal order quantity, reorder point and optimal routes for each product).

In order to answer to those questions, a sensitivity analysis is achieved.

This sensitivity analysis will be performed by testing various scenarios under limited 
and unlimited reserve capacity ${ }^{5}$. The scenarios will differ from one another by the variation applied to the warehouse and inventory cost coefficients. In order to have results which can be interpreted, the variation applied to the different cost coefficients will be no more than $20 \%$.

\subsubsection{Warehouse sensitivity test}

The first sensitivity test concerns the impact of changes in the warehouse cost coefficients on the total savings and on the warehouse and inventory configuration . There exists a dependency between the warehouse cost coefficients. Therefore, the value of the warehouse objective function cost coefficients have been fixed according to their definition and significance.

The warehouse objective function is composed of forward and reserve reception costs, forward and reserve picking costs and advance and concurrent replenishment costs. We know that the forward picking cost is lower than the reserve picking cost. Indeed the forward area is a smaller area than the reserve area where the picking activity can be preformed faster (cheaper) than in the reserve area. On the other hand, the reserve reception cost is lower than the forward reception cost because the replenishment of the reserve area can be technically achieved more easily than in the forward area (by larger sizes or full pallets). Concerning the replenishment activity, advance replenishment is less costly than concurrent replenishment because this activity does not result in creating congestion. Those relations are important otherwise it would not be interesting to have a forward and a reserve area. In addition, the assumptions made on our model would not be valid.(see Section 3.2 for more details)

Therefore, in the sensitivity analysis, we are interested in the impact on the warehouse and inventory cost and on the inventory and warehouse configuration of the relative cost difference between the forward and reserve reception cost, the forward and reserve picking cost and the advance and concurrent replenishment costs. Therefore, we have three relative cost differences in our first sensitivity scenario, each taking three possible values. For each of these twenty seven sensitivity scenarios, we have decided to consider two extreme values.

Table 7 gives the minimum, average and maximum total savings, in percentage, obtained with the different sensitivity scenarios (i.e by varying the value of the warehouse objective function cost coefficients) and with different capacity limits. Most of the difference in the total savings (except in the case of the second integration with limited capacity) are relatively stable with no more than $1 \%$ difference between the maximum and minimum total savings for a certain capacity limit and a certain type of integration. By analyzing in more details the results obtained with the different sensitivity scenarios, we observe that the optimal order quantity and reorder point do not change from one scenario to the other. Only in the case of limited capacity, we can observe that the routes taken by the various products

\footnotetext{
${ }^{5}$ The appendix gives a complete description of the different scenarios
} 


\begin{tabular}{|c|c|c|c|}
\hline & \multicolumn{3}{|c|}{ Total Cost Savings (\%) } \\
\hline \multirow{3}{*}{ First } & Min & $\begin{array}{c}\text { Unlimited Reserve } \\
\text { Capacity }\end{array}$ & $\begin{array}{c}\text { Limited Reserve } \\
\text { Capacity }\end{array}$ \\
\cline { 2 - 4 } integration & average & 0 & 8.67 \\
\cline { 2 - 4 } Second & Max & 0 & 8.90 \\
\cline { 2 - 4 } & Min & 0.06 & 9.10 \\
\cline { 2 - 4 } integration & Max & 0.096 & 11.00 \\
\cline { 2 - 4 } & Max & 0.16 & 13.89 \\
\hline
\end{tabular}

Table 7: Results of the warehouse sensitivity analysis.

are different from one sensitivity scenario to the other.

An exception can be observed in the case of limited capacity when the integrated heuristic solution procedure is used. In this case, we can observe a difference of more or less $4 \%$ between the minimum and maximum total savings realized. This observation can be explained by two remarks. First of all, the methodology used in the heuristic integrated procedure. Indeed, in order to solve the inventory model, we have developed a procedure which uses the subgradient algorithm (see Section 4.2 for more details). As said in Section 4.2, the subgradient algorithm will be stopped after a finite number of iteration without improvement in the value of the objective function. This stopping criteria does not guarantee that the lagrangian relaxation of the inventory problem is solved to optimality which can explain the result obtained with the different sensitivity scenarios. Secondly, with the heuristic integrated solution procedure, the changes in the forward and reserve reception cost are taken into account at the inventory and the warehouse level. Indeed, this change is updating the forward and reserve reception cost and the reserve and forward capacity constraints in the inventory model during the successive iterations. Consequently, minor changes of the optimal ordered and reorder point (sometime no changes are remarked) are observed combined with changes in the optimal route for each product.

\subsubsection{Inventory and warehouse sensitivity test}

The second sensitivity test that we have considered is the relative importance of the total inventory cost compare to the total warehouse cost (and conversely). The aim is to analyse the impact of those changes on the value of the total savings realized with the first and the second integration and on the warehouse and the inventory configuration (i.e the optimal order quantity, reorder point and route for each product). During computational tests, we have observed that there is no impact on the optimal order quantity, optimal reorder point and the optimal routes for each product but there is an impact on the costs. Table 8 gives the minimum, 
average and maximum impact, in percentage, on the total savings realized with the first and the second integration.

\begin{tabular}{|c|c|c|c|}
\hline & \multicolumn{3}{|c|}{ Total Cost Savings (\%) } \\
\hline \multirow{3}{*}{ First } & Min & $\begin{array}{r}\text { Unlimited Reserve } \\
\text { Capacity }\end{array}$ & $\begin{array}{c}\text { Limited Reserve } \\
\text { Capacity }\end{array}$ \\
\cline { 2 - 4 } & average & 0 & 25.83 \\
\cline { 2 - 4 } integration & Max & 0 & 36.51 \\
\hline \multirow{3}{*}{ Second } & Min & 0.24 & 43.96 \\
\cline { 2 - 4 } & average & 0.41 & 30.08 \\
\cline { 2 - 4 } & Max & 0.54 & 39.64 \\
\hline
\end{tabular}

Table 8: Results of the inventory and warehouse sensitivity analysis.

\subsubsection{Inventory sensitivity test}

The last sensitivity test analyses the impact on the inventory, warehouse configuration and on the total savings of changes in the inventory objective function cost coefficients. This sensitivity analysis is important. On the one hand, changes in the inventory carrying cost and acquisition cost can occur because the value of the product changes(e.g. reevaluation of taxes, insurance ...). On the other hand, the shortage and carrying cost is difficult to estimate [12].

Computational tests have been performed and several remarks can be made.

\begin{tabular}{|c|c|c|c|}
\hline & \multicolumn{3}{|c|}{ Total Cost Savings (\%) } \\
\hline \multirow{3}{*}{ First } & Min & $\begin{array}{c}\text { Unlimited Reserve } \\
\text { Capacity }\end{array}$ & $\begin{array}{c}\text { Limited Reserve } \\
\text { Capacity }\end{array}$ \\
\cline { 2 - 4 } integration & average & 0 & -6.85 \\
\cline { 2 - 4 } & Max & 0 & 11.00 \\
\hline \multirow{3}{*}{ Second } & Min & 0 & 36.32 \\
\cline { 2 - 4 } & average & 0.01 & 0 \\
\cline { 2 - 4 } & Max & 0.036 & 15.89 \\
\hline
\end{tabular}

Table 9: Results of the inventory sensitivity analysis.

In the case of unlimited reserve capacity, we know that the inventory cost 
function is relatively flat around the optimal ordered quantity. This observation means that small changes in the optimal order quantity and reorder point will not have a significant impact on the total savings. This is confirmed by the value obtained with the sensitivity test in the case of unlimited reserve capacity (see table 9).

In the case of limited capacity, the impact on the total savings of changes in the inventory cost coefficients can be much more important. Indeed, modifications in the inventory cost coefficients will have an impact on the optimal order quantity, reorder point and optimal route of each product. This modification will also have an indirect impact on the value of the lagrangian coefficients through the capacity constraint (see Section 4 for more details) which leads to a larger modification of the order quantity and a larger impact on costs. Two particular situations can be pointed out. First of all, in some cases, no savings are obtained with the second integration. This can be observed when the modification in the inventory cost coefficients are such that the reserve capacity limite becomes unlimited (due to a decrease in the optimal order quantity and reorder point for each product). Secondly, we can observe in Table 9 that the minimum value obtained for the total savings with the first integration is negative. This is due to the approximation made with the global capacity constraint of the heuristic sequential procedure. In fact, this global capacity constraint overestimate the need of capacity. Therefore, sometimes, the heuristic sequential procedure estimates that capacity is missing whereas in reality (when the forward and reserve capacity are considered separately) there is enough capacity. In this particular case the heuristic uncapacited method performs better than the heuristic sequential method.

\section{Conclusion}

Currently, most of the tactical warehouse and inventory issues are tackled independently and sequentially. Our aim through this paper was to show the value of integrating more decisions of the warehouse and inventory fields. Consequently, we have presented a global model which takes into account the replenishment decision at the inventory management level, the allocation of products to warehousing systems and the assignment of products to storage locations at the warehousing management level. In order to solve this global model, we have presented two heuristics which illustrate two possible levels of integration.

In the first heuristic solution procedure, the inventory and warehouse models are solved sequentially, but the inventory model is taking into account a global capacity constraint for the entire warehouse. This global capacity constraint reflects the limited space in the warehouse but neither the routes taken by the products nor the number and capacity of the locations in the forward area are considered in the inventory model.

In the second heuristic solution procedure, a higher level of integration is achieved by considering two capacity constraints, one for each area in the warehouse (forward and reserve area). This made possible to take into account the 
routes taken by the products, the number and capacity of the locations in the forward area. This second heuristic solution procedure is based on an iterative loop of the two subproblems (inventory and warehouse sub model) where the output of one of the model at one iteration becomes the input of the other model at the next iteration.

Computational results were obtained under limited and unlimited capacity situation in the warehouse. It has been shown that under unlimited capacity (limited forward capacity and unlimited reserve capacity), savings could be achieved only by using the second level of integration (second heuristic solution procedure) whereas in the case of limited capacity the major savings were achieved through the first level of integration (first heuristic solution procedure), although the higher level of integration could achieve some additional savings.

A sensitivity analysis was performed to observe the impact of changes in the objective cost coefficients on the total savings realized and on the warehouse and the inventory configuration. Three sensitivity tests were realized. The first test analyses the impact of changes in the warehouse cost coefficients. The second test analyses the impact of changes in the relative importance of the total warehouse cost compare to the total inventory cost. Lastly, changes in the inventory cost coefficients were performed and analyzed. The results show that in most cases changes in the objective cost coefficients were not having a significant impact on the warehouse and the inventory configuration and the total savings realized. Nevertheless, two exceptions were observed. The first exception occurred when the warehouse cost coefficients were modified. In the case of limited capacity, the results obtained for the inventory model with the heuristic integrated method were not very stable. This is due to the methodology used to solve the inventory model and to the higher level of integration between the inventory and the warehouse models.

The second exception is discovered when the inventory cost coefficients are changed and when the reserve capacity is limited. In this case, sometimes, the integrated procedure is not better than the heuristic uncapacited method and the heuristic sequential procedure was performing worse than the heuristic uncapacited method. 


\section{References}

[1] G.P. Broulias, E.C. Marcoulaki, G.P. Chondrocoukis, and L.G. Laios. Warehouse management for improved order picking performance: an application case study from the wood industry. Department of Industrial Management \& Technology, University of Piraeus, 2005.

[2] Jeroen P. Van den Berg, Gunter P. Sharp, A.J.R.M. Gademann, and Yves Pochet. Forward-reserve allocation in a warehouse with unit-load replenishments. European Journal of Operational Research, pages 98-113, 1998.

[3] E.H. Frazelle, S.T. Hackman, U. Passy, and L.K. Platzman. The forwardreserve problem. Optimization in Industry 2, pages 43-61, 1994.

[4] Ghiani G., Laporte G., and Musmanno R. Introduction to Logistics Systems Planning and Control. Wiley-Interscience series in systems and optimization, 2004.

[5] Moncer A. Hariga and Peter L. Jackson. The warehouse scheduling problem: formulation and algorithms. IIE Transactions, pages 115-127, 1996.

[6] White J.A and Kinney H.D. Storage and Warehousing. Handbook of Industrial Engineering, 1982.

[7] Johnson L. and Montgomery D. Operation Research in Production Planning, Scheduling, and Inventory Control. John Wiley \& Sons, 1974.

[8] Simon Carl P. and Blume Lawrence. Mathematics for economists. W.W. Norton \& Cy, inc., 1994.

[9] B. Rouwenhorst, B. Reuter, V.Stockrahm, G.J. van Houtum, R.J.Mantel, and W.H.M. Zijm. Warehouse design and control: Framework and literature review. European Journal of Operational Research, pages 515-533, 2000.

[10] Hackman S. and Rosenblatt J. Allocating Items to an Automated Storage and Retrieval System. IIE Transactions, pages 7-14, 1990.

[11] Nahmias S. Production and Operation analysis. McGraw-Hill International Editions, 1997.

[12] Stephen G. Timme and Christine Williams-Timme. The Real Cost of Holding Inventory. Supply Chain Management Review, July 1, 2003.

[13] Jeroen P. van den Berg. A literature survey on planning and control of warehousing systems. IIE transactions, pages 751-762, 1999.

[14] Jeroen P. van den Berg and W.H.M. Zijm. Models for warehouse management: Classification and examples. Int. J. Production Economics, pages 519-528, 1999 .

[15] Carlos J. Vidal and Marc Goetschalckx. A global supply chain model with transfer pricing and transportation cost allocation. European Journal of Operational Research, pages 134-158, 2001. 
[16] Bozer Y.A. Optimizing Throughput Performance in Designing Order Picking Systems. Ph.D. Dissertation, School of Industrial and Systems Engineering, Georgia Institute of Technology, 1985. 


\section{Appendix}

\section{Description of the dataset}

1. Products

\begin{tabular}{|c|c|}
\hline & units \\
\hline Minimum demand mean & 0.015 \\
\hline Average demand mean & 44.85 \\
\hline Maximum demand mean & 636.92 \\
\hline Minimum demand standard deviation & 0.015 \\
\hline Average demand standard deviation & 26180.84 \\
\hline Maximum demand standard deviation & 5073610 \\
\hline \hline Minimum pick mean & 0.015 \\
\hline Average pick mean & 5.57 \\
\hline Maximum pick mean & 44.32 \\
\hline Minimum pick standard deviation & 0.015 \\
\hline Average pick standard deviation & 40.87 \\
\hline Maximum pick standard deviation & 695.54 \\
\hline
\end{tabular}

2. Objective function warehouse and inventory cost description

\begin{tabular}{|c|c|}
\hline reserve reception cost & 5 \\
\hline forward reception cost & 7 \\
\hline advance replenishment cost & 20 \\
\hline concurrent replenishment cost & 25 \\
\hline forward picking cost & 2 \\
\hline reserve picking cost & 10 \\
\hline additional capacity cost & 50 \\
\hline
\end{tabular}

\begin{tabular}{|c|c|}
\hline inventory carrying cost & 3 \\
\hline acquisition cost & 6 \\
\hline shortage cost & 100 \\
\hline
\end{tabular}




\section{Sensitivity analysis : scenario description}

(a) Scenario 1: Warehouse sensitivity test

The relationship between the warehouse cost coefficients can be expressed as followed :

$$
\begin{aligned}
& \text { CostF }=\beta_{1} \times \text { CostR } \\
& \text { PickCostR }=\beta_{2} \times \text { PickCostF } \\
& \text { CostRepC }=\beta_{3} \times \text { CostRepA }
\end{aligned}
$$

We have construct 27 scenarios by varying the $\beta_{1}, \beta_{2}$ and $\beta_{3}$ from 1.5 to 2.5 .

(b) Scenario 2: Inventory and warehouse sensitivity test

We have construct 4 scenarios: the inventory cost being one third, half, three quarter and 1.25 of the warehouse cost.

(c) Scenario 3: Inventory sensitivity test

We have constructed the following relationship:

$$
\begin{aligned}
& \text { CostRecp }=\beta_{4} \times \text { CostCar } \\
& \text { CostShort }=\beta_{5} \times \text { CostCar }
\end{aligned}
$$

We have construct 9 scenarios by varying the $\beta_{4}$ and $\beta_{5}$ from 1.5 to 2.5 . 


\section{Recent titles}

\section{CORE Discussion Papers}

2007/65. Taoufik BOUEZMARNI and Jeroen V.K. ROMBOUTS. Nonparametric density estimation for multivariate bounded data.

2007/66. Hylke VANDENBUSSCHE and Maurizio ZANARDI. What explains the proliferation of antidumping laws?

2007/67. Nihat AKTAS, Eric DE BODT, Ilham RIACHI and Jan DE SMEDT. Legal insider trading and stock market reaction: evidence from the Netherlands.

2007/68. Nihat AKTAS, Eric DE BODT and Richard ROLL. Learning, hubris and corporate serial acquisitions.

2007/69. Pierre-André JOUVET, Pierre PESTIEAU and Gregory PONTHIERE. Longevity and environmental quality in an OLG model.

2007/70. Jean GABSZEWICZ, Didier LAUSSEL and Michel LE BRETON. The mixed strategy Nash equilibrium of the television news scheduling game.

2007/71. Robert CHARES and François GLINEUR. An interior-point method for the single-facility location problem with mixed norms using a conic formulation.

2007/72. David DE LA CROIX and Omar LICANDRO. 'The child is father of the man': Implications for the demographic transition.

2007/73. Jean J. GABSZEWICZ and Joana RESENDE. Thematic clubs and the supremacy of network externalities.

2007/74. Jean J. GABSZEWICZ and Skerdilajda ZANAJ. A note on successive oligopolies and vertical mergers.

2007/75. Jacques H. DREZE and P. Jean-Jacques HERINGS. Kinky perceived demand curves and Keynes-Negishi equilibria.

2007/76. Yu. NESTEROV. Gradient methods for minimizing composite objective function.

2007/77. Giacomo VALLETTA. A fair solution to the compensation problem.

2007/78. Claude D'ASPREMONT, Rodolphe DOS SANTOS FERREIRA and Jacques THEPOT. Hawks and doves in segmented markets: a formal approach to competitive aggressiveness.

2007/79. Claude D'ASPREMONT, Rodolphe DOS SANTOS FERREIRA and Louis-André GERARDVARET. Imperfect competition and the trade cycle: guidelines from the late thirties.

2007/80. Andrea SILVESTRINI. Testing fiscal sustainability in Poland: a Bayesian analysis of cointegration.

2007/81. Jean-François MAYSTADT. Does inequality make us rebel? A renewed theoretical model applied to South Mexico.

2007/82. Jacques H. DREZE, Oussama LACHIRI and Enrico MINELLI. Shareholder-efficient production plans in a multi-period economy.

2007/83. Jan JOHANNES, Sébastien VAN BELLEGEM and Anne VANHEMS. A unified approach to solve ill-posed inverse problems in econometrics.

2007/84. Pablo AMOROS and M. Socorro PUY. Dialogue or issue divergence in the political campaign?

2007/85. Jean-Pierre FLORENS, Jan JOHANNES and Sébastien VAN BELLEGEM. Identification and estimation by penalization in nonparametric instrumental regression.

2007/86. Louis EECKHOUDT, Johanna ETNER and Fred SCHROYEN. A benchmark value for relative prudence.

2007/87. Ayse AKBALIK and Yves POCHET. Valid inequalities for the single-item capacitated lot sizing problem with step-wise costs.

2007/88. David CRAINICH and Louis EECKHOUDT. On the intensity of downside risk aversion.

2007/89. Alberto MARTIN and Wouter VERGOTE. On the role of retaliation in trade agreements.

2007/90. Marc FLEURBAEY and Erik SCHOKKAERT. Unfair inequalities in health and health care.

2007/91. Frédéric BABONNEAU and Jean-Philippe VIAL. A partitioning algorithm for the network loading problem.

2007/92. Luc BAUWENS, Giordano MION and Jacques-François THISSE. The resistible decline of European science. 


\section{Recent titles}

\section{CORE Discussion Papers - continued}

2007/93. Gaetano BLOISE and Filippo L. CALCIANO. A characterization of inefficiency in stochastic overlapping generations economies.

2007/94. Pierre DEHEZ. Shapley compensation scheme.

2007/95. Helmuth CREMER, Pierre PESTIEAU and Maria RACIONERO. Unequal wages for equal utilities.

2007/96. Helmuth CREMER, Jean-Marie LOZACHMEUR and Pierre PESTIEAU. Collective annuities and redistribution.

2007/97. Mohammed BOUADDI and Jeroen V.K. ROMBOUTS. Mixed exponential power asymmetric conditional heteroskedasticity.

2008/1. Giorgia OGGIONI and Yves SMEERS. Evaluating the impact of average cost based contracts on the industrial sector in the European emission trading scheme.

2008/2. Oscar AMERIGHI and Giuseppe DE FEO. Privatization and policy competition for FDI.

2008/3. Wlodzimierz SZWARC. On cycling in the simplex method of the Transportation Problem.

2008/4. John-John D'ARGENSIO and Frédéric LAURIN. The real estate risk premium: A developed/emerging country panel data analysis.

2008/5. Giuseppe DE FEO. Efficiency gains and mergers.

2008/6. Gabriella MURATORE. Equilibria in markets with non-convexities and a solution to the missing money phenomenon in energy markets.

2008/7. Andreas EHRENMANN and Yves SMEERS. Energy only, capacity market and security of supply. A stochastic equilibrium analysis.

2008/8. Géraldine STRACK and Yves POCHET. An integrated model for warehouse and inventory planning.

\section{Books}

Y. POCHET and L. WOLSEY (eds.) (2006), Production planning by mixed integer programming. New York, Springer-Verlag.

P. PESTIEAU (ed.) (2006), The welfare state in the European Union: economic and social perspectives. Oxford, Oxford University Press.

H. TULKENS (ed.) (2006), Public goods, environmental externalities and fiscal competition. New York, Springer-Verlag.

V. GINSBURGH and D. THROSBY (eds.) (2006), Handbook of the economics of art and culture. Amsterdam, Elsevier.

J. GABSZEWICZ (ed.) (2006), La différenciation des produits. Paris, La découverte.

L. BAUWENS, W. POHLMEIER and D. VEREDAS (eds.) (2008), High frequency financial econometrics: recent developments. Heidelberg, Physica-Verlag.

P. VAN HENTENRYCKE and L. WOLSEY (eds.) (2007), Integration of AI and OR techniques in constraint programming for combinatorial optimization problems. Berlin, Springer.

\section{CORE Lecture Series}

C. GOURIÉROUX and A. MONFORT (1995), Simulation Based Econometric Methods.

A. RUBINSTEIN (1996), Lectures on Modeling Bounded Rationality.

J. RENEGAR (1999), A Mathematical View of Interior-Point Methods in Convex Optimization.

B.D. BERNHEIM and M.D. WHINSTON (1999), Anticompetitive Exclusion and Foreclosure Through Vertical Agreements.

D. BIENSTOCK (2001), Potential function methods for approximately solving linear programming problems: theory and practice.

R. AMIR (2002), Supermodularity and complementarity in economics.

R. WEISMANTEL (2006), Lectures on mixed nonlinear programming. 